\title{
Gliptine als Knochenheiler
}

\author{
DDP-4-Hemmer könnten künftig nicht nur den Blutzucker bei Patienten mit Diabetes Typ 2 \\ senken, sondern auch die Knochenheilung bei älteren Menschen mit Übergewicht verbessern. \\ Eine aktuelle Studie unter Führung des Deutschen Instituts für Ernährungsforschung (DIfE), \\ einem Partner des DZD, ergab nämlich, dass bestimmte Zellen im Knochenmark enorme \\ Mengen an DPP 4 produzieren und so nach einer Fraktur die Heilung behindern können.
}

Seit längerem ist bekannt, dass Alterungsprozesse Übergewicht begünstigen können. Dabei sind diese Prozesse nicht nur von vermehrten Ablagerungen weißer Fettzellen in den regulären Fettdepots wie dem Unterhautfettgewebe begleitet. Sie tragen auch zu übermäßig großen Fettzell-Ansammlungen in anderen Gewebstypen bei, zum Beispiel im Knochenmark. Wie jüngste Studien annehmen lassen, stehen solche Veränderungen mit Osteoporose, einem erhöhten Risiko für Knochenbrüche sowie einer gestörten Ausreifung der Immun- und Blutzellen im Knochenmark im Zusammenhang.

Zudem weisen andere Untersuchungen darauf hin, dass Menschen mit Typ-2-Diabetes besonders zu Knochenbrüchen neigen. Die biologischen Mechanismen, die all diesen Beobachtungen zu Grunde liegen, sind jedoch bislang noch nicht hinreichend erforscht. Daher gingen die Wissenschaftler in einer aktuell publizierten Studie den zellulären und molekularbiologischen Ursachen dieser Prozesse mithilfe von Zellexperimenten und Untersuchungen an Mäusen auf den Grund.

\section{Fettreiche Ernährung im Alter führt zur Fettansammlung im Knochen}

Wie die Forscher erstmals zeigen, führt eine fettreiche Ernährung, besonders im fortgeschrittenen Alter, dazu, dass sich im Knochenmark vermehrt spezialisierte (Fett-)Vorläuferzellen ausbreiten, die letztlich zur Fettansammlung im Knochen beitragen. Diese beeinträchtigen die Knochenheilung und Blutbildung im Knochenmark der langen Röhrenknochen. Hinzu kommt, dass im Alter generell die Knochenzellentwicklung gestört ist. Die Untersuchungen bestätigen Erkenntnisse aus früheren Studien und könnten erklären, warum Knochenbrüche im Alter schlechter heilen, besonders dann, wenn die Patienten aufgrund einer fettreichen Ernährungsweise übergewichtig sind.

Darüber hinaus haben die Forscher ein erstes molekulares Bindeglied identifiziert, das die negative Wirkung der Fettzellen auf die Regenerationsfähigkeit der Knochen vermittelt. Es handelt sich um das eiweißspaltende Enzym Dipeptidyl-Peptidase 4 (DPP 4). DPP 4 baut bekanntlich unter anderem GLP 1 ab, ein Hormon, das den Zuckerstoffwechsel stark beeinflusst. Dies begünstigt einerseits hohe Blutzuckerwerte und beeinträchtigt zum anderen die Funktion der Insulin produzierenden Zellen der Bauchspeicheldrüse. Basierend auf diesen Erkenntnissen wurden Gliptin-Präparate entwickelt, die die Wirkung von DPP 4 auf den Blutzuckerspiegel mindern und sich in der Diabetestherapie etabliert haben. Die neuen Untersuchen zeigen nun, dass DPP 4 eine wichtige Rolle für die zelluläre Knochenzusammensetzung spielt, was ein neues Einsatzfeld für die DPP-4-Inhibitoren eröffnen könnte.

\section{Diabetes mit erhöhtem Frakturrisiko assoziiert}

Die Forschungsergebnisse weisen also auf einen direkten Zusammenhang zwischen Stoffwechselerkrankungen und der Anfälligkeit für Knochenbrüche hin. Sie liefern zudem einen ganz neuen therapeutischen Ansatzpunkt, um die Regenerationsfähigkeit der Knochen insbesondere bei alten, übergewichtigen Menschen medikamentös zu verbessern. Dabei ist es besonders günstig, dass DPP-4-Hemmer bereits seit Jahren in der Diabetestherapie etabliert und gut untersucht sind.

Neben diesen unmittelbar medizinisch relevanten Erkenntnissen zeigen die Forscher in umfangreichen zellbiologischen Arbeiten, dass die Zusammensetzung der Ernährung die Stammzellen des Knochens direkt beeinflusst und bestimmt, ob aus ihnen Knochen- oder Fettvorläuferzellen entstehen. In künftigen Studien soll daher z.B. geprüft werden, inwiefern bestimmte Ernährungsformen und Nahrungsmittelinhaltstoffe eingesetzt werden könnten, um die Knochenheilung zu unterstützen. Aber auch ohne Medikamente kann man viel für seine Knochengesundheit tun, einfach indem man auf ein nor-

Originalie

Ambrosi T H, Scialdone A, Graja $A$ et al. Adipocyte accumulation in the bone marrow during obesity and aging impairs stem cell-based hematopoietic and bone regeneration.

Cell Stem Cell. 2017 Jun

1;20(6):771-784.e6. doi:

10.1016/j.stem.2017.02.009.

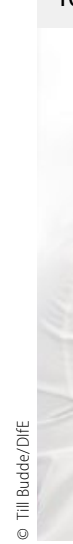

Das Fluorescence Activated Cell Sorting analysiert Fettvorläuferzellen. males Körpergewicht und eine ausgewogene Ernährung achtet, worauf Prof. Tim Schulz und Thomas Ambrosi, die beiden Hauptautoren der Studie, besonders hinweisen.

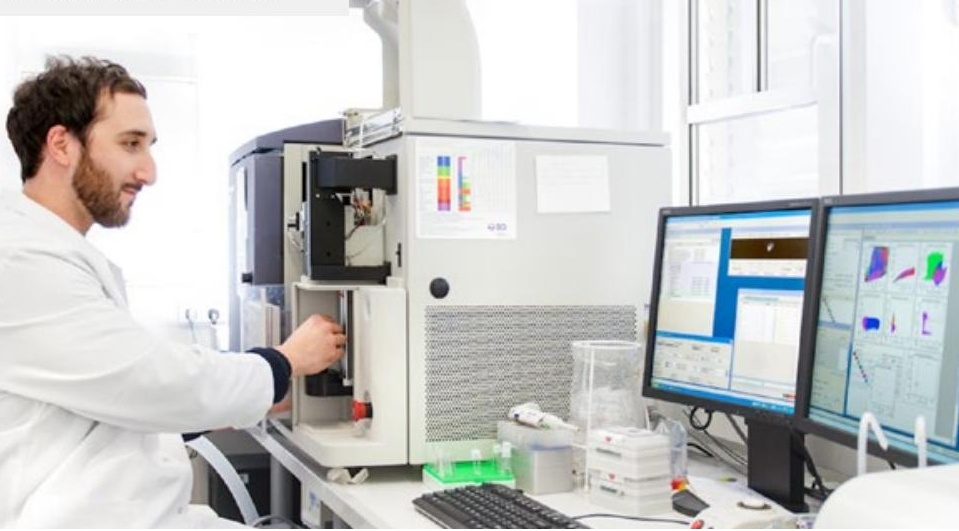

